\title{
El Almirantazgo y la BaHía de CÁdiz EN la BAJa EdAD \\ MEDIA: COMPETITIVIDAD SEÑORIAL, RENTAS \\ ALIENADAS Y PROYECTOS FRUSTRADOS.
}

\section{THE AdMIRALSHIP AND THE BAY OF CÁdIZ IN THE LATE MIDDLE AGES: LORDLY COMPETIVITY, ALIENATED RIGHTS AND FRUSTRATED PROJECTS.}

\author{
LORENZO LAGE ESTRUGO \\ lorenzo.lage@uca.es
}

UNIVERSIDAD DE CADIZ ${ }^{1}$

http://dx.doi.org/10.25267/Riparia sup.2019.i2.06

\section{RESUMEN}

El almirantazgo castellano es una de las instituciones más problemáticas en suelo peninsular debido a las grandes disputas por la aplicación de su jurisdicción. Durante el siglo XV, esta debilidad institucional se hace manifiesta con la consolidación del proceso de señorialización de Andalucía Occidental, epicentro de los intereses del almirantazgo. Examinando la casuística de la bahía de Cádiz puede observarse la realidad de la gestión de toda una serie de derechos que, pese al interés del almirante o sus representantes, eran frecuentemente usurpados o estorbados.

Palabras Claves: Almirantazgo. Bahía de Cádiz. Finales de la Edad Media. Señorialización. Rentas.

\footnotetext{
1 Becario FPU. Historia Medieval. Departamento de Historia, Geografía y Filosofía. Facultad de Filosofía y Letras, Avda. Gómez Ulla, s/n, 11003, Cádiz, ESPAÑA.

L. Lage Estrugo, «El Almirantazgo y la Bahía de Cádiz en la Baja Edad Media: competitividad señorial, rentas alienadas y proyectos frustrados», Suplemento RIPARIA 2 (2019, 143-172.
} 


\section{Abstract}

The Castilian Admiralship is one of the most troublesome institutions in Peninsular soil, owing to the great disputes around the application and implementation of its jurisdiction. During the 15th century, this institutional weakness was exposed as result of Andalucía Occidental becoming a tangle of different lordships, fruit of a lording process; this affected the Admiralship greatly, considering the said región was the core of its interests. Examining the Bay of Cádiz as a particular case we can, thus, observe the reality of the management of an assortment of rights that, not minding the interest of the admiral and his representatives, were frequently usurped or alienated.

KeYwords: Admiralship. Bay of Cádiz. Late Middle Ages. Lordships. Incomes and rights. 


\section{La teoría frente a la realidad.}

El Almirantazgo, como institución, sufre una transformación sustancial a lo largo del siglo XV: frente a los almirantes como agentes activos de la política naval del siglo $\mathrm{XIV}$, los Enríquez entienden su oficio como una prebenda, una cuestión patrimonial, convirtiéndose, por ello, en agentes pasivos. Dicha cuestión definirá el oficio a lo largo del final de la Edad Media, y, por ende, caracteriza muchos de los problemas que surgen en torno a dicha figura institucional.

La Bahía de Cádiz, por otro lado, supone un marco sociopolítico y geográfico óptimo para el análisis del ejercicio de los derechos del almirantazgo y sus problemáticas en dicho momento histórico. Sin duda, hay que entender la región como un paisaje político complejo, como paisaje de una sociedad compleja y muy diversificada ${ }^{2}$. El espacio sobredicho, de Cádiz y su bahía, a finales de la Edad Media conforma un paisaje muy estratificado, con numerosos agentes políticos, sociales y económicos organizando y dividiendo el entorno natural en diferentes demarcaciones que, además, interactúan entre sí dentro de un todo sistémico que, a su vez, está interconectado con otros grandes sistemas socio-económicos y socio-políticos del corredor Mediterráneo-Atlántico ${ }^{3}$. Así pues, el almirante de Castilla es un agente más dentro del conjunto de agentes transformadores y organizadores del espacio geográfico-político de la Bahía de Cádiz, y sus acciones contribuyen a una gestión concreta del

\footnotetext{
2 Sobre la caracterización del paisaje, y la definición de paisaje políticos, véase, por ejemplo: P. López Paz, G. Pereira Menaut, "La Tierra y los Hombres: paisaje político, paisaje histórico", Studia Historica: Historia Antigua, 13, 1995, p. 56.

${ }^{3}$ Emilio Martín señala dichas conexiones interregionales y la presencia de elementos extranjeros como agentes comerciales en la región en: E. MARTín GuTIÉRREZ, "El Estrecho de Gibraltar durante el siglo XIV: medio ambiente y redes comerciales en Algeciras", Revista del CEHGR, 30, 2018, 52-54; 61-65. Véase, a su vez, para pormenores de dichas conexiones entre Andalucía y el espacio Atlántico: E. AzNAR VAllejo, “Andalucía y el Atlántico Norte a finales de la Edad Media”, En la España medieval, 37, 2014, 105-109.
} 
espacio y sus recursos. No hay que obviar esta concepción del espacio como un paisaje político complejo, ya que el marco geográfico es un elemento esencial en todo estudio histórico que se precie: en este caso, la especificidad de la región, la Andalucía Occidental costera, define los modos de interacción de los agentes sociales, políticos y económicos dentro de sí misma.

Cádiz no solo se encuentra en un marco geográfico estratégico, como espacio de transición de los mundos Atlántico y Mediterráneo, sino que, además, cuenta con recursos propios de gran valor económico y social: en lo agrícola contamos con una producción de cereales destacable, con una rica producción de aceite y con, también, una potente industria vitivinícola; dentro del marco de los productos relacionados con el mar la región no sólo contaba con grandes salinas, sino también con salazones, unas muy prósperas almadrabas y considerables flotas pesqueras ${ }^{4}$. Dichos recursos proporcionaban, naturalmente, toda una serie de rentas y beneficios asociados cuya gestión se dividían la mencionada serie de agentes públicos y privados, y de los cuáles, en buena medida, buscaba aprovecharse el almirante mediante la aplicación de sus elementos jurisdiccionales y su

\footnotetext{
4 Por ejemplo, los ingresos derivados de la pesca no harían sino ascender a lo largo del siglo XV. Los duques de Medinaceli y Medina Sidonia percibían enormes ingresos derivados de su control de grandes flotas pesqueras, almadrabas y caladeros. En 1512 el duque de Medinaceli percibía 903.750 maravedíes de las actividades pesqueras del Puerto de Santa María: en 1522 habían ascendido a 1.017.750 maravedíes; A. FRANCO Silva, "Los pescadores del Puerto de Santa María y sus problemas a comienzos del siglo XVI", Historia, Instituciones, Documentos, 22, 1995, 191-192. Los Guzmanes poseían por privilegio de 1292 al mismísimo Guzmán el Bueno de todas las almadrabas desde el Guadiana a la frontera con Granada; A. SARrí́ MuÑoz, I. PÉREZ DE Colosía RoDríguez, "Las almadrabas del duque de Medina Sidonia en Tarifa", Baetica. Estudios de Arte, Geografía e Historia, 13, 1991, 248. No es de extrañar que desde 1445 a 1457 los Enríquez reclamasen el derecho de clavar almadrabas en Tarifa; ibídem. Además, el propio almirante tenía el privilegio de mantener cien pescadores francos en nómina, como se demuestra en un mandato presentado por Rodrigo Álvarez de la Becerra, lugarteniente, de 1456; Archivo General de Andalucía, Alba, C. 77-61.
}

«El Almirantazgo y la bahía de Cádiz en la Baja Edad Media: competitividad...» 
control, teórico, sobre el comercio y las actividades económicas en regiones litorales.

Pero, debemos antes realizar un breve resumen de la institución del almirantazgo en sí misma para comprender la naturaleza de las interacciones del almirante y sus agentes con el medio natural y socio-político caracterizado, esto es, el Arzobispado de Sevilla, y el Obispado de Cádiz, centrándonos en particular en el espacio geográfico de la Bahía de Cádiz. Primeramente, la institución se enmarca en un marco teórico de carácter generalista y universal: ello crea una dicotomía clara entre el plano de unas atribuciones teóricas de carácter inclusivo y el de una realidad donde las prácticas particulares creaban campos de exclusividad que, claramente, rehuían la influencia del almirantazgo como una fuerza centrípeta. Frente a las aspiraciones centralistas, al menos en apariencia, y universalistas del almirantazgo se oponen toda una serie de poderes públicos y privados, individuales y colectivos, con los cuales la institución y sus oficiales deben o bien contemporizar o bien entrar en conflicto abierto, emprendiendo numerosos pleitos y reclamaciones, con resultado variable. La teorizada universalidad de la institución queda así mediatizada por la existencia de agentes externos que condicionan no sólo la expansión de su esfera de actuación real, sino que incluso entorpecen, usurpan o perturban el día a día de la institución. La forma más sencilla de anular la influencia del almirantazgo era denegando la entrada de sus agentes en una localidad, pero había obstáculos más difíciles de sortear por su carácter abstracto y en ocasiones fruto de realidades contrapuestas; como el choque entre diversas jurisdicciones en un espacio y un momento concretos. En ello influye, determinantemente, la difícil realidad socio-económica y socio-política de la corona castellano-leonesa en el siglo XV, y, en especial, la de la propia Andalucía del momento, dividida en 
grandes señoríos, grandes demarcaciones concejiles y en zonas de realengo ${ }^{5}$.

Segundo, ¿qué atribuciones teóricas debía desempeñar el almirantazgo en la Bahía de Cádiz? Tenía, en primer lugar, la capacidad de juzgar todos los casos civiles y criminales relacionados con el mar, para lo cual existían unos tribunales propios con sede en Sevilla, teniendo el almirante la potestad, incluso, de llevar a cabo la pena capital; tenía incluso un patíbulo propio. Dicha capacidad jurisdiccional, pues, abarcaba todos los llamados hombres de la mar, esto es, todos los individuos cuyo oficio estaba relacionado con las actividades marinas, desde un simple marinero a un cómitre, pasando por un armador o incluso un mercader. El almirante, o, en su defecto, su representante legal y jurídico, tenía la atribución teórica de dispensar justicia sobre un colectivo bastante numeroso de personas, tanto más en un marco geográfico como el conformado por el obispado de Cádiz y el arzobispado de Sevilla, donde una parte importante de la población activa consagraba su actividad profesional al mundo marino. Aún más, hay que tener en cuenta la existencia del triángulo Jerez de la Frontera-Cádiz-Puerto de Santa María, que creaba un conglomerado portuario y productivo con un enorme potencial económico y muy volcado al escenario atlántico y las actividades marinas, desde la pesca al comercio de larga distancia, pasando por el comercio de carácter local ${ }^{6}$. En segundo lugar,

${ }^{5}$ Los señoríos de la Bahía de Cádiz han sido estudiados por numerosos historiadores. Dentro de la zona tenemos el gran concejo de Jerez, sujeta únicamente al rey, las villas señoriales de Sanlúcar, el Puerto de Santa María, Chipiona, Cádiz, San Fernando, Medina Sidonia y Tarifa, sumando a ello los otros lugares de realengo de menor entidad, como Puerto Real. Véanse: D. García Hernán, "Los señoríos en la Baja Andalucía en la Edad Moderna", Los señoríos en la Andalucía Moderna. El Marquesado de los Vélez (coords.), Almería, 2007, 78-83; M. A. LADERO QueSADA, "Los señores de Andalucía. Investigaciones y señoríos en los siglos XIII a XV”, Cádiz, 1998; A. COllantes de TERÁn SÁNCHEZ, "Los señoríos andaluces: análisis de su evolución territorial en la Edad Media”, Historia, Instituciones, Documentos, 6, 1979, 89-112.

6 Enrique Ruiz Pilares ha caracterizado este triángulo productivo en varios de sus trabajos, incluyendo: E. Ruiz PILARES, "Jerez de la Frontera: el gran centro productor

«El Almirantazgo y la bahía de Cádiz en la Baja Edad Media: competitividad...» 
asociadas a su jurisdicción sobre los "hombres de mar", encontramos otra serie de atribuciones, fundamentalmente económicas y rentistas, como el cobro de un porcentaje del quinto real (un tercio), derechos sobre la saca de pan, sobre la saca de aceite, la saca de las cosas vedadas o sobre la propia construcción naval y el flete de navíos.

Dichas cuestiones son elementos con un potencial económico de primer nivel dentro de Andalucía occidental, uno de los corazones económicos de la corona castellano-leonesa. Únicamente con su influencia teórica sobre una cuestión tan relevante como la saca del pan, el almirante debía poseer una importancia señalada sobre la vida económica de la región, tanto más cuando era un elemento muy relevante para el abastecimiento de las ciudades de la zona, ya que ante períodos de escasez agentes municipales podían adquirir pan en otras localidades. Ello, a su vez, estaba relacionado con el control de la saca de las cosas vedadas, siendo el pan una de las mercancías cuya comercialización estaba prohibida fuera de las fronteras del reino, tanto en dirección a Portugal, con el cual había una encendida rivalidad política y comercial, como en la de Granada o el Magreb ${ }^{7}$. Comercio éste, el de las cosas vedadas, que incluía

del complejo portuario de Cádiz a finales de la edad media", Estudios sobre patrimonio, cultura y ciencias medievales, 20, 2018, 356-358; E. RUIz PILARES, "La sociedad jerezana y su implicación en el comercio atlántico: la producción y el comercio del vino (finales s. XV-inicios s. XVI)", J.A. Solórzano Telechea, B. Arizaga Bolimburu, M. BOCHACA (eds.), Las sociedades portuarias de la Europa atlántica en la Edad Media, Logroño, 2016, 338-343.

${ }^{7}$ Las restricciones a la saca de pan eran frecuentes, pero en tiempos de enfrentamiento abierto, absolutamente imprescindibles, al ser producto estratégico. Por ejemplo, el 17 de febrero de 1478 se expide licencia para sacar pan a un buen número de personajes señalados, empezando por "Alfonso Enrriques almirante mayor de la mar e su logarteniente" y siguiendo por "Enrrique de Gusman duque de Medina Sidonia", a todos cualesquiera lugares, villas y ciudades, pero se les prohíbe sacar pan a "tierra de moros", Portugal o Francia. Ello se enmarca en la Guerra de Sucesión castellana, que terminará en 1479. Archivo General de Simancas, Registro General del Sello, LEG,147802,44. 
productos como el oro, el hierro, la madera o las armas, y cuyo control teórico quedaba reservado al almirantazgo ${ }^{8}$.

Las atribuciones teóricas del oficio y las de sus titulares oscilaron a lo largo del tiempo. Hay que comprender que dichas potestades jurisdiccionales dependen en buena medida de la autoridad de la corona y su colaboración con la institución. En períodos de debilidad estatal es una misión bastante complicada mantener los derechos del almirantazgo: hemos de tener en cuenta los flotantes derechos asociados a dicha institución dependían, en buena medida, del apoyo regio en la resolución de pleitos. La carencia de una autoridad sólida por parte del almirantazgo se observa claramente en la documentación producida durante el período en cuestión, ya que los mandatos de la corona, en muchas ocasiones reiterativos y continuos, parecen indicar una realidad compleja, donde los derechos del dicho oficio son continuamente alienados.

También, hay que considerar los derechos que el propio almirante o sus agentes intentaban acaparar, basándose en la universalidad, teórica, de la institución, lo cual por otra parte suponía una transgresión de otras jurisdicciones. Por ejemplo, el almojarifazgo, sito en Sevilla, tenía importantes funciones aduaneras, funciones que agentes del almirante se apresuraron a obviar, y viceversa, habiendo agentes del almojarife mayor que

8 Una relación de los derechos del almirantazgo fue remitida en forma de capítulo a Alonso de Valladolid, criado del almirante, por parte de éste en 1455, para que éste los arrendase a Rodrigo Álvarez de la Becerra, vecino de Sevilla, "fijo de Diego Alvares", que también fue arrendador. Los derechos enumerados serían "guindaje e ramate de los toneles e mercaderías", los derechos de la saca de pan en el "arçobispado de Sevilla e obispado de Cadis" y en el "condado [de Niebla]" y en las villas de Fuenterrabía, San Sebastián y Cartagena. También se incluyen los derechos sobre la exportación de esclavos "canaryos e canaryas" y la potestad de elegir los cómitres en Jerez, Cádiz, Sevilla y Santa María del Puerto. Son derechos amplios, a los cuales se añaden las cosas vedadas, el ancoraje, el embarque y desembarque, y los quintos de presas, no mencionados en el capítulo al reservárselos el almirante. Archivo General de Andalucía, Alba, C. 58.

«El Almirantazgo y la bahía de Cádiz en la Baja Edad Media: competitividad...» 
usurpaban elementos jurisdiccionales del almirantazgo. Juan de Haro, vecino de Ciudad Real, tenía, a fines del siglo XV, arrendado el almojarifazgo mayor, y elevó una queja en 1488 ante los Reyes Católicos por el comportamiento del lugarteniente de almirante, que había usado de manera abusiva sus prerrogativas para recaudar tasas de los navíos que entraban en el puerto sevillano. La reina Isabel procuró enviar tajante mandato al respecto, prohibiendo se realice dicha actividad recaudatoria por considerarse una imposición injusta sobre el volumen comercial sevillano; literalmente se dice causaría "deserviçio" a la corona en general ${ }^{9}$. Dicho pleito, llamativamente, es entre dos arrendadores: ellos eran, al fin y al cabo, quienes llevaban a cabo el día a día de sus respectivos oficios y la administración de sus derechos. Finalmente, la vida económica del reino sevillano, y por ende de la monarquía castellana, y los intereses de los mercaderes, con los beneficios asociados, priman por encima de las pretensiones universalistas del almirantazgo. Ello no quiere decir que todos los pleitos fallaran a favor del almojarifazgo, siendo también lo contrario falso, hay un continuo juego de equilibrios muy delicado, garantizado por la corona; en buena medida, posible por el atento gobierno de los asuntos de estado por parte de los monarcas Isabel y Fernando. Cuando la corona atraviesa períodos complejos, el almirante sufre un menoscabo de sus derechos. Por ejemplo, el intento de Juan Pacheco de controlar a la nobleza andaluza y aglutinarla en torno a sí en los años finales del reinado de Enrique IV provocará la cesión de regalías y privilegios, que en buena medida anulaban aquellos del almirantazgo. El duque de Medina Sidonia, cercano al partido del príncipe Alfonso,

\footnotetext{
9 Traslado de una cédula de 1488 a petición del mencionado Juan de Haro, arrendador y recaudador mayor del almojarifazgo mayor y de Berbería. El recaudador dice que el lugarteniente de almirante se entrometía en sus asuntos dando albalá de "mercaderías e otras cosas que salen por la mar e por el río", cosas que el alega no pertenecían al almirante, a quién sólo adscribe las cosas vedadas, literalmente. Archivo General de Andalucía, Alba, C. 77-79.
} 
obtendrá privilegios varios, incluyendo el cargo y descargo en todas sus villas:

"Don Alfonso (...) por quanto vos don Iohán de Guzmán, mi tío, duque de Medina Sidonia, conde de Niebla, mi vasallo, e de mi Conseio (...) que ami plogiese de confirmar e confirmase vna carta de don Enrrique, mi anteçesor os dio çerca del cargo e descargo de vuestras villas, e logares, que tenedes en los puertos de la mar. E yo (...) vos confirmo et apruebo, e vos lo ratifico, la dicha merçed que así el dicho don Enrrique, mi anteçesor, vos dio çerca del dicho cargo e descargo de las dichas vuestras villas e logares (...) E mando a qualesquier personas a quien se dirige la dicha carta que la guarden e cunplan e non vayan, nin pasen, nin consientan ir nin pasar contra ella en algund tiempo ni por alguna manera (...) dada en la noble villa de Valladolid, veinte e cinco días de julio, anno del nasçimiento del Nuestro Sennor Ihesu Christo de mille e quatroçientos e sesenta e cinco annos" ${ }^{10}$.

Y en 1467 recibirá por parte del mismo príncipe-rey Alfonso las tercias del pan de Trebujena, Sanlúcar, Condado de Niebla con Bollullos, Almonte y Huelva y Medina Sidonia con su tierra y término, aunque no en su persona, sino en la de su hijo, Enrique de Guzmán ${ }^{11}$. El duque de Medinacelli, Luis de la Cerda, ganará a su vez privilegios por su villa del Puerto de Santa María $^{12}$. Dichas concesiones, muchas veces, y como hemos

10 Transcripción completa en A. M. AnASAgasti VAlderrama, "Niebla y su tierra en la Baja Edad Media: historia y documentos”, Huelva, 2006, 787.

11 Ídem, 803-805.

12 Luis de la Cerda suplicó al príncipe Alfonso que le librase de los juros que éste tenía sobre rentas regias del Puerto. Véase: J. M. García Avoso, "Poder y conflicto en un señorío atlántico castellano. El pleito del condado de el Puerto de Santa María en los inicios de la Edad Moderna", Historia, Instituciones, Documentos, 45, 2018, 31-32. Por otro lado, los Ponce de León señoreaban Cádiz, que pese a su escasa vecindad era una plaza mercantil importante con colonias de mercaderes estantes extranjeros. R. SÁNCHEZ SAUS, "Dependencia señorial y desarrollo urbano en la Andalucía atlántica. Cádiz y los Ponce de León en el siglo XV", Acta histórica et archaelogica mediaevalia, 26, 2005, 905-906. En relación con esto último, se cuentan 21 mercaderes de origen genovés en el padrón

«El Almirantazgo y la bahía de Cádiz en la Baja Edad Media: competitividad...» 
apuntado, anulaban de manera efectiva los derechos del almirante ${ }^{13}$, y son sólo una muestra de los extensos privilegios que gozaban los grandes magnates regionales y la extensión de sus jurisdicciones.

Frente a estas cuestiones se erige otro elemento muy a tener en cuenta: el desinterés personal de los almirantes del linaje Enríquez en ejercer una autoridad real o directa sobre los asuntos del almirantazgo, conectado con una desvinculación física con los propios negocios que debía presidir. El Almirante tenía asiento en el consejo real y, sucesivamente, los Enríquez prefirieron residir en la corte y adoptar un papel cortesano, imbricándose en las numerosas intrigas que se sucedieron durante los reinados de Juan II y Enrique IV. Los almirantes llegaron a ostentar la mayordomía mayor del reino y un asiento en el consejo real: dicho oficio procuraba un acceso a la persona del monarca y, por su parte, el asiento en el consejo un rol en la alta política ${ }^{14}$. El papel cortesano, frecuentemente, excluía su rol como almirante, al menos desde un punto de vista práctico, teniendo en cuenta, que, la presencia del receptor del oficio en el lugar de desempeño

gaditano de 1467 y la relación de vecinos de 1468. E. MArTín GutiÉrrez, "Nuevos datos sobre la población y los genoveses en la ciudad de Cádiz: una relectura del padrón de vecinos de 1467”, En la España Medieval, 29, 2006, 194.

13 El duque de Medina Sidonia llegaría a conseguir de manos de Enrique IV los derechos de almojarifazgo en sus posesiones de Lepe, la Redondela, Ayamonte y Huelva en 1469. Lo cual no hacía sino complementar los que ya tenía en la propia Sanlúcar de Barrameda. J. M. Bello León, "Los beneficiarios de la Hacienda Real. Privilegios, situados y libranzas en el almojarifazgo mayor de Sevilla a finales del siglo XV. Algunos datos cuantitativos", M. de las M. Borrero Fernández, J. Carrasco Pérez, R. G. Peinado Santaella (coords.) Agentes de los sistemas fiscales en Andalucía y los reinos bispánicos (siglos XIII-XVII), Madrid, 2014, 213-214.

14 Así aparece mencionado el almirante Alonso Enríquez en un privilegio regio, como mayordomo mayor y consejero regio. El asiento en el consejo irá asociado al almirantazgo, ya que su hijo y heredero también lo ostentará. Su asociación con el gobierno central culmina con su papel de co-gobernador del reino junto con Adriano de Utretch y el condestable, Íñigo Fernández de Velasco, durante las Comunidades. Afortunadamente, en Simancas se conservan las cartas intercambiadas entre Adriano y Fadrique en 1520, demostrando su influencia política en ausencia de Carlos I; Archivo General de Simancas, Patronato Real, PTR,LEG,1,DOC.96. 
de la jurisdicción de dicha dignidad era un elemento importante para la afirmación de sus propios derechos. A ello se añade que los intereses patrimoniales del linaje no se encontraban próximos a los intereses del almirantazgo en el reino de Sevilla, estando en dos ámbitos geográficos muy diferentes. Los Enríquez tenían la mayor parte de sus posesiones territoriales en el núcleo de la vieja Castilla, en torno a la villa de Medina de Rioseco: el propio testamento de Alonso Enríquez, es un excelente ejemplo de la escasa conexión territorial de los titulares del almirantazgo con el epicentro de los intereses del dicho oficio ${ }^{15}$. A su hijo Fadrique, Alonso Enríquez lega en su codicilo testamentario (junto con el almirantazgo y la veinticuatría de Sevilla a él asociado) las villas de Medina de Rioseco, Torrelobatón, Aguilar, Villabrágima, Tamariz, Valdenebro, Villabañez, Berrueces, Villalba, Villanueva, Bustillo, Zorita y Simancas, todas ellas próximas entre sí, conformando un núcleo de posesiones territoriales considerable en la actual provincia de Valladolid, la mayor parte de dichas villas encontrándose en la región denominada como Tierra de Campos. Dentro de los legados paternos a su sucesor en el almirantazgo, no se encuentra ninguna posesión territorial concreta en el ámbito andaluz. El único elemento ligado estrictamente al ámbito sevillano es la receptoría del diezmo del aceite de Sevilla, por la cual le correspondían setecientos quintales al almirante ${ }^{16}$. Podemos observar, por tanto, un distanciamiento total con respecto a la realidad andaluza, ya que el solar de la

\footnotetext{
15 Archivo Histórico de la Nobleza, Osuna, C.495,D.8.

${ }^{16}$ Los derechos sobre el diezmo del aceite de Sevilla y su receptoría son un privilegio regio de 1475, tras lo cual los almirantes ostentaron dicha dignidad, como elemento patrimonial; véase, Archivo General de Andalucía, Alba, C. 77-70. Los setecientos quintales del diezmo del aceite adjudicados a los almirantes fueron incluso arrendados a mercaderes italianos, como puede verse en un arrendamiento de 1485 a Polo Ondegardo, Clerico de Neglo y Andrea Odón, milanés el primero (vecino de Valladolid) y genoveses los dos siguientes (estantes en Toledo y Sevilla, respectivamente). Se implica en el documento que Odón, estante en Sevilla, llevaría el peso de la gestión. Además, un arrendamiento bastante largo, por seis años. Archivo General de Andalucía, Alba, C. 96.
}

«El Almirantazgo y la bahía de Cádiz en la Baja Edad Media: competitividad...» 
dinastía está en Valladolid. Dicha división entre intereses jurisdiccionales y patrimoniales jugará un rol fundamental en la perspectiva adoptada por los almirantes del linaje con respecto a su propio oficio. La posesión del señorío de Tarifa hubiera podido solventar la deficiencia y carencia de un señorío andaluz propio que asentara el poder del linaje dentro de Andalucía occidental, pero los Enríquez se desligaron de él después de su definitiva afirmación de dominio sobre la villa y señorío, enmarcado en el amplio conjunto de negociaciones que sellaron el matrimonio de Beatriz Per Afán de Ribera y Pedro Enríquez, a quien le fue cedido, creando una nueva rama colateral con intereses andaluces ligados al Adelantamiento Mayor de Andalucía, la línea de los marqueses de Tarifa ${ }^{17}$, que sí se establecieron como un gran linaje andaluz y sevillano.

\section{La problemática del Almirantazgo: competitividad y alienación.}

Hay que tener en cuenta que el almirantazgo como institución únicamente tiene un campo de actuación determinado en Andalucía occidental, mientras que, fuera de ella, su incidencia es débil o rechazada de manera contundente. Los vecinos de Málaga, Marbella y otros lugares del reino de Granada se quejaban de manera muy elocuente acerca de la reciente imposición de la jurisdicción del almirante en sus localidades, así como expresan elocuentemente el tenor de la cuestión:

\footnotetext{
17 El señorío de Tarifa fue ostentando por los Saavedra de 1448 a 1478, momento en el cual la rebelión del cabeza de linaje provocó su revocación. Tarifa fue otorgada a Pedro Enríquez y su esposa, Catalina de Ribera; no hay que olvidar las importantes conexiones de ambos, ya que la madre de Catalina era María de Mendoza, condesa de los Molares y hermana del cardenal Pedro González de Mendoza M. A. LAdero Quesada, "De Per Afán de Ribera a Catalina de Ribera. Siglo y medio en la historia de un linaje sevillano (1371-1514)", En la España medieval, 4, 1984, 471. La rivalidad entre ambas familias se ve exacerbada por la concesión de la alcaldía de las cosas vedadas a Gonzalo de Saavedra en 1445 por Juan II y Álvaro de Luna.
} 
“(...) fue suplicado para ante mí, y en grado de la dicha suplicación presentaron ante los de mi Consejo çiertas peticiones en que dixeron (...) que la mi carta de previllegio hera contra ellos muy injusta e agraviada e dynna de rrevocar por las rrazones siguientes. Lo primero porque las dichas çibdades de Granada e Málaga e las otras çibdades e villas del dicho Reyno de Granada son francas por cartas e previllegios (...) y que poner agora tan grand ynpusiçión sería cosa grave (...) de que los vecinos de dichas çibdades e de todo el dicho Reyno de Granada rresçebería grand daño e perjuicio e se yrían a bevir a otras partes, e porque todas las mares de Vizcaya e Guipuzcoa e la costa e Asturias e Galizia e en Reyno de Murçia y en algunos lugares del Reyno de Andaluzía el dicho Almirant non lleva derechos nin tiene juridiçión, e que sy el dicho Reyno de Granada los llevase por nueva ynpusiçión paresçería cosa grave porque los dichos derechos son inmensos e inmoderados, e que a esta cabsa los mercaderes que suelen venir con sus mercaderías a las dichas çibdades e villas del dicho Reyno por no pagar los dichos derechos se pasan con sus mercadorías al Reino de Portugal como agora a paresçido por espiriençia que lo hacen (...)"18

Como vemos, hay un rechazo frontal a las imposiciones jurisdiccionales del almirante, que mayormente eran las que tenía en el reino de Sevilla, con gran énfasis en los aspectos judiciales, civiles y criminales, y en derechos como la saca de pan, que acabarían provocando la revuelta abierta contra el almirantazgo. Ante una queja tan firme, Fernando el Católico, actuado en representación de su hija Juana, haría la concesión de convertir el almirantazgo granadino en una dignidad vitalicia; "durante la vida del dicho Almirante don Fadrique Enrriquez de Cabrera e no más, la guardedes e cunplades e fagades cumplir en todo e por todo" $"$. Claro que, los vecinos de dichas ciudades no se

18 Transcripción extraída de: J. M. CALDERÓn ORTEGA, "El almirantazgo de Castilla: historia de una institución conflictiva”, Alcalá de Henares, 2003, 403-404.

${ }^{19}$ Ibídem.

«El Almirantazgo y la bahía de Cádiz en la Baja Edad Media: competitividad...» 
esperaban el almirante fuera a vivir hasta 1536. Este es un ejemplo paradigmático del sistemático rechazo que produce la implementación de los derechos del oficio fuera de Andalucía occidental, único ámbito territorial donde tiene poder efectivo. $\mathrm{Y}$ mayormente por el apoyo de la corona. Los representantes urbanos llegan a hablar de menoscabo del comercio y las rentas porque el comercio se desvía a otros ámbitos, sobre todo el portugués, lo cual no es de extrañar teniendo en cuenta ambos espacios funcionan dentro del gran corredor comercial del Estrecho de Gibraltar.

Así pues, los problemas que pudiese encontrar en el reino de Sevilla definían el éxito relativo de la implementación de dicha jurisdicción. Los numerosos derechos y prebendas que poseía la institución convertían al almirantazgo en una fuente de rentas, al menos en teoría, muy considerable, teniendo en cuenta los derechos percibidos del tráfico marítimo y de la actividad bélica en el Estrecho, así como los propios beneficios derivados del ejercicio de la justicia, como los ingresos obtenidos de multas y embargos. Por ello, si en la región contaba con obstáculos, el ejercicio de obtención de rentas quedaba anulado, y por tanto, el nivel de ingresos acababa considerablemente reducido. Teniendo en cuenta el afán rentista de los Enríquez con respecto a la institución a lo largo del siglo $\mathrm{XV}$, no es de extrañar se esforzasen, al menos mediante terceros, con que el ejercicio de los derechos y deberes de su oficio fuesen respetados, lo cual conllevó a un sin número de conflictos por todo el reino de Sevilla con los más diversos agentes ${ }^{20}$. Hay que considerar que

${ }^{20}$ Hay conflictos con los almojarifes, los miembros del concejo sevillano, los oidores,
los jueces, señores de la región (Estúñiga, Guzmán, Ponce de León) e incluso hay
conflictividad entre los propios representantes del almirantazgo. Por su recurrencia
destacan los justicias y los asistentes de Sevilla, que usurpaban las labores
jurisdiccionales del almirante sobre los hombres de mar, lo cual conllevaba la
expedición de numerosas cédulas por parte de la corona e incluso del Adelantado
Mayor, Pedro Enríquez. El 14 de febrero de 1485 hay un despacho del Adelantado
conminando a los justicias y asistentes para que no usurpen la jurisdicción del 
dentro del conjunto del reino sevillano la Bahía de Cádiz es uno de los grandes núcleos económicos, pero, también y a su vez, destacaba como uno de los puntos de mayor conflictividad para el almirantazgo, teniendo en cuenta los fuertes intereses confluyentes en la zona, fruto de la progresiva señorialización del territorio a lo largo del siglo XV. Así, los grandes obstáculos para la implementación de la sobredicha jurisdicción fueron, principalmente, los grandes (y reiterados) señores de la zona, los Ponce de León y los Guzmanes, duques de Arcos y de Medina Sidonia, respectivamente. Dicha rivalidad incluía, pues, la obstrucción de numerosas iniciativas de los almirantes en la región, tanto más cuando controlaban de facto buena parte de los concejos de la Bahía, a través de sus agentes o afines, quienes procuraban favorecer los intereses de dichos magnates ${ }^{21}$.

Las localidades que no eran directamente posesiones de alguno de $\operatorname{ambos}^{22}$ estaban bajo su influencia directa ${ }^{23}$. El

almirantazgo. A su vez ello está en relación con una cédula inserta de los Reyes Católicos del 20 de agosto de 1484, dada en Córdoba "al adelantado mayor, justiçias, asistentes e veinticuatro (...)", en la cual les ordena cesen de estorbar la labor del lugarteniente en la carga y descarga de mercancías. Archivo General de Andalucía, Alba, C. 95.

${ }^{21}$ La división en bandos de la Baja Andalucía es un fenómeno de sobras conocido, así como los acostamientos que convertían los concejos en el coto privado de los grandes nobles, que tenían en su nómina a corregidores, veinticuatros y buenos hombres de numerosas villas, sin contar con el control directo que poseían en su señorío. Las disputas en torno al dominio de lugares como Jerez provocaron, incluso, enfrentamientos abiertos entre los Ponce de León y los Guzmán. En el caso de esta ciudad vemos excelentes ejemplos trabajados por Enrique Ruiz Pilares, como el de los Villavicencio, que por ser parte de la facción de los Medina Sidonia llegaron a sufrir destierro o prisión cuando el marqués de Cádiz tomó la ciudad en 1471. E. RuIz Pilares, "El mayorazgo del veinticuatro Pedro Camacho de Villavicencio 'el rico' (1507). El patrimonio del caballero jerezano más acaudalado de su tiempo", En la España Medieval, 35, 2012, 323-324.

22 El control de estos señores sobre sus villas llegaba a ser casi absoluto. Por ejemplo, el concejo de Sanlúcar, caput de las posesiones del duque de Medina Sidonia, gestionaba únicamente cuestiones de poca monta, como el pavimentado de la fuente pública o inquirir sobre el precio de la carne en Jerez, mientras que el duque se reservaba la gestión de los grandes temas, como el comercio o la pesca, que no dejan huella

«El Almirantazgo y la bahía de Cádiz en la Baja Edad Media: competitividad...» 
Almirante quien no tenía una base de apoyos, una red clientelar extensa o presencia patrimonial y territorial equiparables en la región, tenía que sufrir, pues, el menoscabo continuo de sus intereses por parte de ambos señores. En contrapartida tenía el respaldo y el peso legal del capítulo de privilegios otorgado a los almirantes por la corona desde el siglo XIV, y sobre todo durante el reinado de los Reyes Católicos el apoyo explícito y continuado de los propios monarcas ${ }^{24}$. Pese a todo, los reyes tampoco podían alienar a los dos más poderosos magnates de la región, lo cual convertía todo el asunto en un delicado juego de intereses e influencias punteado de numerosos pleitos y conflictos.

Considerando los factores arriba mencionados, el almirante recurría frecuentemente a individuos pertenecientes a las élites locales como sus representantes en la región. La delegación de poderes era una forma de solucionar, al menos parcialmente, la desconexión del almirante con sus intereses en Andalucía occidental, además, que dichos delegados perteneciesen a la oligarquía de la zona permitía que la institución

destacable en la documentación municipal sanluqueña. Véase: Archivo Municipal de Sanlúcar de Barrameda, Actas Capitulares, Libro I, 1511-1516.

23 Se conserva un libro de cuentas ducal, debido a la administración regia de las posesiones de los Guzmanes entre 1509-1513. En él figuran cuarenta y cinco vasallos, acostados, que reciben anualmente alguna suma del duque, en total, 154.175 maravedíes, con montos que van desde los 30.000 de Diego Osorio a personajes que cobran sumas inferiores a 10.000. Aunque dentro del monto total es una cantidad pequeña, hay que considerar que el duque estaba exiliado en Portugal en aquel entonces y es un momento crítico de su influencia; probablemente en tiempos de Juan de Guzmán, III duque de Medina Sidonia, los gastos serían mayores. J. M. NAvarro SAINZ. "Aproximación a los gastos señoriales de la casa de los duques de Medina Sidonia a principios del siglo XVI", Huelva en su historia, 3, 1990, p. 184.

${ }^{24}$ La corona, a su vez, tras la conquista de Granada busca puertos desde los cuales intensificar la presencia castellana en África. Los puertos andaluces occidentales habían quedado bajo señoríos: "por eso [la corona] compró parte de la jurisdicción sobre Palos en 1492 y recuperó la de Cádiz en 1493 (...) En 1502, Gibraltar volvería también al realengo, después de haber sido administrado durante unos decenios por la casa ducal de Medina Sidonia", M. García Arenal, M. A. DE Bunes, "Los españoles y el Norte de África. Siglos XV-XVIII", Madrid, 1992, 37. La búsqueda de plazas costeras bajo realengo fue también fue la razón de la fundación de Puerto Real en 1483. 
aprovechase sus redes de influencia. La fórmula de delegación usual fue el arrendamiento, además por plazos de tiempo relativamente extensos y estables. La duración de dichos contratos, e incluso la continuidad dentro de individuos del mismo linaje muestra una continuidad y una estabilidad que favorecía los intereses del oficio dentro de la región ${ }^{25}$. La incidencia de estos personajes no debe ser, de ningún modo, desdeñada, ya que eran realmente la cara visible del almirantazgo, su representante legal. Como contrapartida, el arrendamiento podía tener resultados irregulares o incluso negativos, ya que podía conllevar una cierta rapacidad por parte de dichos delegados o incluso una mala gestión podía desordenar durante años el delicado equilibrio jurisdiccional en la región. La ventaja evidente era la presencia de dichos individuos sobre el terreno, además, y usualmente, personajes con cierto dominio de las tareas que les correspondían como delegados institucionales del almirante; la carencia de habilidad personal podía ser solventada por el nivel de influencia del arrendador o sus redes clientelares. Teniendo en cuenta la duración de algunos de los contratos y la explícita relación de confianza del almirante de turno con alguno de los arrendadores, de sus lugartenientes, podemos afirmar que, al menos aparentemente, fue un sistema de gestión eficiente; todo lo eficiente que puede ser una delegación de poder y funciones de dicha índole. Estos individuos tienen mayor relevancia si consideramos que eran ellos y no el almirante quienes debían lidiar con el día a día de la institución y hacer frente a los problemas y conflictos ocasionados por la práctica de la

\footnotetext{
25 Sólo hay que analizar los algunos de los nombres de los arrendadores y lugartenientes conocidos: Álvarez de la Becerra, Barba, Cabeza de Baca, Marmolejo, Ortiz de Gatica. Todos ellos pertenecen a linajes medios dentro de sus ciudades, aunque varios fueron veinticuatro (Luis Fernández de Marmolejo o Luis Ortiz de Gatica) o estuvieron emparentados de manera directa con algunos miembros de los gobiernos urbanos de Jerez o Sevilla. Su pertenencia a la oligarquía local facilitaba, pues, el desempeño del oficio, usando las redes familiares y clientelares existentes. Para una lista de casi todos los lugartenientes sevillanos, véase: J. M. CALDERón OrTEGA, "El almirantazgo de Castilla: historia de una institución conflictiva”, Alcalá de Henares, 2003, 213.
}

«El Almirantazgo y la bahía de Cádiz en la Baja Edad Media: competitividad...» 
implementación de la jurisdicción del almirantazgo. Así pues, no es de extrañar que el lugarteniente de almirante fuese quien hubo de sufrir en su propia persona las consecuencias del largo y encendido conflicto del duque de Medina Sidonia con los titulares del almirantazgo, siendo agredido en su propia casa de la ciudad hispalense ${ }^{26}$.

\section{La influencia del almirante en la bahía de Cádiz.}

Hay que distinguir diferentes ámbitos de actuación, la comarca jerezana, la propia ciudad de Cádiz, las villas "menores" como el Puerto de Santa María, Rota o Sanlúcar y la villa de Tarifa, vinculada personalmente con los almirantes y su linaje. En dichas poblaciones la influencia del almirante se hacía sentir de manera diferente y de modo cambiante a lo largo del tiempo. Los diferentes titulares del almirantazgo intentarán asentar su influencia en la zona, con éxito variable: la manera de aumentar la autoridad de la institución en el lugar no era sino ganando influencia dentro de los concejos de la zona. Los concejos, a su vez, eran una fuerza de oposición considerable, pues podían llegar a bloquear por completo la percepción de diversas rentas que pertenecían legítimamente al almirante. Villas costeras y portuarias como Cádiz o el Puerto de Santa María podían llegar a rechazar representantes y oficiales del almirantazgo o negarse a pagar alguno de los derechos a la institución debidos, o podían no colaborar en la medida de lo requerido ${ }^{27}$.

\footnotetext{
${ }^{26}$ Se conservan las órdenes del duque para inspeccionar las casas del almirantazgo en Sevilla por parte de sus agentes, pero también es conocido el memorial de agravios de Fernando de Ribadeneira, que describe los daños ocasionados por parte de los agentes de Guzmán al almirantazgo y sus derechos, de 1448, en el cual el lugarteniente habla de cómo el duque embarca y desembarca mercancías por su cuenta y no paga derecho alguno. Ya en 1445 había ordenado dicho noble el registro de las casas del almirantazgo en Sevilla. Archivo General de Andalucía, Alba C.111-24; Archivo General de Andalucía, Alba, C.77-44.

27 Por ejemplo, un requerimiento de Luis Ortiz de Gatica, 1505, lugarteniente de almirante, al justicia del Puerto de Santa María para que se encontrase y penase a quien hubiera vendido ciento noventa y cinco espadas guarnecidas en tierra de moros, y que se había interceptado en un barco, escondidas en dos fardos. Se incluye la respuesta de
} 
Las ciudades y villas costeras andaluzas frecuentemente tenían quejas de los derechos del almirantazgo, en los cuales veían simplemente un menoscabo y rémora para la actividad económica del lugar, un sobrecosto añadido a las otras imposiciones fiscales; los numerosos pleitos y quejas elevados por varias localidades a lo largo y ancho de la península ibérica demuestra la propensión a no pagar los derechos del oficio y su consideración como una exacción abusiva. Claramente, y desde el punto de vista de cualquiera involucrado en el comercio de la época, toda imposición adicional que encareciese la actividad económica debía ser, per se, considerada como abusiva y, por tanto, rechazada. La propia ciudad de Sevilla, uno de los corazones económicos de la corona castellano-leonesa, mantuvo frecuentes encontronazos con los representantes del almirante.

El gran obstáculo jurisdiccional del almirante, el duque de Medina Sidonia posiblemente veía en la jurisdicción del almirante un menoscabo de sus propios privilegios y derechos, así como una cortapisa a sus ambiciones políticas y marítimas. Juan Alonso Pérez de Guzmán, III duque de Medina Sidonia, llegó a tomar la ciudad de Melilla en 1497. Esas cabalgadas y razias a lo largo de la costa marroquí debían generar pingues beneficios en manera de presas, incluyendo tanto naves como esclavos, y según lo establecido legalmente, al rey le correspondía un quinto de dichas mercancías, pero al almirante le correspondía, a su vez, un tercio de dicho quinto. Lo cual venía a significar que el duque de Medina Sidonia debía legalmente hacer pago de una parte de los beneficios de dichas incursiones al Almirante, lo cual, por supuesto, era una cuestión que el titular del ducado gaditano buscó evitar. Ello puede verse en el largo pleito entre Pedro de Estopiñán, persona del entorno del duque, y los agentes del

los justicias por parte de Antón de Arcos, que hacían todo lo posible por satisfacer el requerimiento sin menoscabar la jurisdicción de su señor, el duque de Medinacelli. Archivo General de Andalucía, Alba, C. 87-2.

«El Almirantazgo y la bahía de Cádiz en la Baja Edad Media: competitividad...» 
almirantazgo, que reclamaban el pago beneficios sobre los quintos derivados de la actividad bélica en el Norte de África ${ }^{28}$. Si el almirante conseguía inmiscuirse en los asuntos del duque, esto supondría un menoscabo de los beneficios percibidos por dicha actividad, algo claramente inadmisible para el duque, lo cual conllevó el inicio de pleitos, como el anteriormente mencionado, por los representantes del oficio para la recuperación de las rentas alienadas en dicho proceso. El segundo duque, Enrique de Guzmán, además, recibió nombramiento como Capitán General de la Mar y Costas de Andalucía en 1489, lo cual, por otra parte, reconocía tanto su importancia militar y estratégica como la carencia de éstas mismas por parte del almirante ${ }^{29}$.

Sevilla se erige en un ejemplo sintomático de la resistencia intrínseca al almirantazgo y sus agentes por todo el occidente andaluz, los concejos, naturalmente indispuestos a la intervención de un magnate castellano con intereses meramente rentistas en la vida económica de sus villas, también se veían negativamente influidos por los grandes nobles castellanos que rivalizaban por el control de la región y que, naturalmente, no iban tampoco a admitir la presencia de otro potencial competidor. Los derechos del almirantazgo así eran continuamente alienados o anulados no sólo por los gobiernos ciudadanos de ciudades como Cádiz o Jerez, sino también en las propias posesiones directas de los grandes señores locales, como Rota o Sanlúcar de Barrameda;

\footnotetext{
28 Exactamente, un pleito entre los herederos de Estopiñán y Luis Ortiz de Gatica, lugarteniente del almirante en Jerez, por una cabalgada en Orán de 1496, en el contexto de la expansión ultramarina del duque de Medina Sidonia. E. Aznar Vallejo, "Las rentas del almirantazgo castellano. Entre la ley y la costumbre", En la España medieval, 37, 2014, 143. Las reclamaciones de quintos serán frecuentes, en el fondo ducal de Alba, sólo en 1495 hay tres reclamaciones, muy cercanas en el tiempo, por parte de Francisco de Villadiego, apoderado del almirante, todas de finales de febrero, una de ellas siendo bastante importante, sobre el importe obtenido de la captura de treinta y cinco esclavos y esclavas en África.

${ }^{29}$ M. Gambín GarcíA, "Una ayuda inesperada. La decisiva intervención del duque de Medina Sidonia en las conquistas de Tenerife y Melilla (1496-1497)", Revista de Historia Canaria, 196, 2014, 183.
} 
villas donde los agentes del almirante tenían difícilmente influencia efectiva. En un momento determinado, Alonso de Valladolid, quién puede considerarse uno de los más eficientes de los lugartenientes de almirante, criado personal de los Enríquez y enviado a la zona para deshacer los entuertos del oficio, fue incapaz de cobrar el tercio del quinto íntegramente de manos del concejo de Cádiz, que se opuso al pago de dichos derechos en los términos exigidos por el almirante, con la siguiente respuesta:

“(...) e dixeron que ellos non podían mandar nin acudir con toda la dicha terçia parte del dicho señor Almirante por las rrazones que se syguen. La primera porque quando esta çibdat es previllejada de lo non pagar como nunca lo pagó de tanto tiempo acá que memoria de onmes non es en contrario, asý por tener conmo tienen previllejos e usos e costumbres, conmo por merçed que tienen del señor Rey don Juan (...) e aun por quanto conmo dicho tenemos nunca se pagó e sy se ha pagado ase pagado de un año acá, lo qual nunca se pagó syno la meytad del dicho terçio del dicho quinto, e esto por quanto la cibdat quiso conplazer al dicho señor almirante" 30 .

Es decir, no sólo la ciudad se opone a pagar las reclamaciones del almirante sobre los quintos de presas, sino que además alega no había costumbre de pagar dichos derechos en Cádiz. Ello es significativo, ya que parece indicar una total inexistencia de la jurisdicción del almirantazgo en ciertos momentos del siglo XV. Teniendo en cuenta que durante la década de 1440 el oficio de almirantazgo se haya en buena medida perdido por causa de la caída en desgracia de don Fadrique Enríquez, partidario de Juan II de Aragón, no es de extrañar que concejos como el gaditano hubieran rechazado pagar cualquier tipo de derechos asociados durante un período de

30 Transcripción completa en J. M. CALderón OrTegA, "El almirantazgo de Castilla: historia de una institución conflictiva”, Alcalá de Henares, 2003, 367.

«El Almirantazgo y la bahía de Cádiz en la Baja Edad Media: competitividad...» 
tiempo relativamente largo. El envío de Alfonso de Valladolid, criado del almirante y cuyo patronímico nos remite a los estados patrimoniales de los Enríquez en el corazón de Castilla, podría responder a la necesidad de restablecer la jurisdicción del almirantazgo y poner en orden sus asuntos; el citado criado del almirante dejará concluidos varios negocios, entre ellos el arrendamiento del oficio a Rodrigo Álvarez de la Becerra, que actuará como lugarteniente de almirante desde dicha fecha.

No hay que olvidar que una de las mayores y más importantes atribuciones del almirante y de sus delegados es, precisamente, el ejercicio de la justicia sobre los hombres de la mar y los asuntos marítimos. Teniendo únicamente en cuenta la relevancia simbólica de dispensar justicia en la Edad Media ello ya sería una cuestión fundamental, pero hay que añadir los potencialmente cuantiosos beneficios derivados, ya que los ingresos de multas, embargos y confiscaciones de bienes podían a llegar a proveer unas sumas elevadas. Sin embargo, ello precisamente hacía que la justicia fuese un elemento muy disputado, con numerosos agentes y organismos reclamando la primacía de sus propias jurisdicciones sobre aquella del almirantazgo. Los almirantes no fueron los únicos en beneficiarse de concesiones y privilegios a lo largo del siglo XV, otros grandes magnates tenían una influencia incluso superior sobre sus propias posesiones, como he reiterado a lo largo del texto, lo cual anulaba de facto toda posible injerencia del almirante en sus posesiones. Los duques de Medina Sidonia, por ello, se habían convertido, así, en los más acérrimos oponentes a la imposición de la jurisdicción del almirantazgo, ya que contaban con regalías y privilegios cuya aplicación necesariamente excluían al almirante y sus representantes. Por ejemplo, el duque de Medina Sidonia tenía sus propios alcaldes de mar, oficiales con dotes judiciales, en sus orígenes individuos conocedores del fuero de la mar y por tanto capaces de juzgar con criterio los casos relacionados con toda actividad marítima. Lógicamente, y, teniendo en cuenta la 
potestad del almirantazgo de juzgar todos los fechos de la mar y el río, que el duque de Medina Sidonia contase con sus propios alcaldes de la mar, que eran además independientes de la jurisdicción de los alcaldes de la mar y los alcaldes mayores del propio almirantazgo, era una suplantación y/o anulación prácticamente total de la jurisdicción de dicha institución castellana en las posesiones del duque. Para evitar una anulación o alienación de sus derechos los Enríquez dependían, nuevamente, de la buena voluntad de la corona e incluso de que la propia autoridad de la corona fuese efectiva en la zona.

El obispado de Cádiz era el área donde el almirantazgo debía de tener teóricamente una influencia significativa, teniendo en cuenta que la fachada atlántica, hacia Portugal y hacia África era un escenario económico de primer nivel, más considerando que el entramado portuario y productivo de la provincia era en sí mismo un núcleo económico de primer orden. Dentro del obispado, sin embargo, el almirantazgo parece haber tenido una influencia mucho más señalada en Jerez que en la propia Cádiz. En documentos relativos a la jurisdicción del almirantazgo primero se señala la ciudad y arzobispado de Sevilla y luego se menciona la villa de Jerez, después incluyéndose el resto de localidades. Teniendo en cuenta que Jerez era una villa de realengo, favorecida por Enrique IV y su privado Juan Pacheco, no es de extrañar que el almirante tuviese una influencia más directa, o que al menos a través del continuado favor regio tuviese una mayor libertad de actuación en Jerez que en las demás villas de la zona. Hacia la segunda mitad del siglo XV empiezan a aparecer lugartenientes en la ciudad, lo cual puede indicar un reconocimiento de la influencia real de Jerez en la esfera económica y comercial $^{31}$. La influencia del almirante, sin ser

31 Alvar Núñez Cabeza de Vaca en 1455 era tanto regidor de la ciudad como lugarteniente de almirante. Ello, singularmente, provocó un conflicto con el lugarteniente sito en Sevilla, el ya mencionado Rodrigo Álvarez de la Becerra, lo cual ocasionó un curioso intercambio epistolar en que se acusan mutuamente de ser

«El Almirantazgo y la bahía de Cádiz en la Baja Edad Media: competitividad...» 
fundamental, llegó a cristalizarse con el nombramiento de Fadrique Enríquez, como veinticuatro de Jerez tras la supresión de la revuelta de las Comunidades, nombramiento que delegó en su lugarteniente, Luis Ortiz de Gatica, inmediatamente. La ciudad de Jerez además era donde residía el guarda mayor de la saca del pan, Pedro de Pinos, que era regidor de la ciudad en $1475^{32}$. La importancia ya reseñada de dicha saca de pan hace aún más interesante que presencia del supervisor general de dicho tráfico en la ciudad de Jerez. Sin duda alguna, y por las cuestiones mencionadas, dicha villa, y no otra, parece señalarse en la documentación del almirantazgo como el centro neurálgico del triángulo productivo Jerez-el Puerto de Santa María-Cádiz, ya que es la única villa de la zona que cuenta con su propio lugarteniente. Por tanto, Jerez y no otra villa parece ser el eje de la administración de los derechos del oficio y la ciudad desde donde se pueden controlar de manera más efectiva estafas, alienaciones $\mathrm{y}$ transgresiones en el litoral andaluz.

\section{Consideraciones finales}

La debilidad institucional del almirantazgo es manifiesta, habiendo una dependencia continuada del apoyo de la justicia regia en la resolución de pleitos. Una aplicación fluida de los derechos reales en una villa o región iba acompañada de una gestión con menos cortapisas para los gestores de los derechos del almirantazgo, el porqué es evidente, teniendo en cuenta que muchas de las regalías otorgadas a los almirantes estaban frecuentemente asociadas a derechos reales, como el quinto, y que la corona era la única que podía garantizar los derechos de la institución sobre los derechos de grandes nobles locales. Una

ilegítimos representantes del almirante en la zona. Véanse las tomas de posesiones del almirante en Sevilla y Jerez, que caracterizan un poco la dinámica existente entre ambos núcleos. Archivo General de Andalucía, Alba, C. 77-51, 53, 55.

32 I. Montes Romero-Camacho, "Las instituciones de la "saca" en la Sevilla del siglo XV. Aproximación al estudio de la organización institucional del comercio exterior de la corona de Castilla al final de la Edad Media", Historia. Instituciones. Documentos, 31, 2004, 432. 
monarquía debilitada, como las de Juan II o Enrique IV sólo contribuía a una progresiva alienación de las rentas de la propia corona y del almirantazgo castellano, tanto más cuando el almirante no contaba, como he reiterado, con una base patrimonial potente en el sur andaluz que le permitiese hacer efectiva su voluntad sin el respaldo constante de la autoridad regia. El reinado de los Reyes Católicos y períodos de crisis entre los grandes nobles de Andalucía, como el producido a las muertes de Juan Alonso de Guzmán y Rodrigo Ponce de León, permitieron una consolidación de los derechos del almirantazgo, que incluso fueron ampliados con la creación del Almirantazgo de Granada en la figura de Fadrique Enríquez de Cabrera, conde de Módica.

Don Fadrique fue ciertamente el último de los Enríquez en buscar ampliar el poder y la influencia del almirantazgo castellano-leonés, y quizás el más activo en dicha empresa y que buscase no sólo asentar el recién creado almirantazgo de Granada sino también el antiguo almirantazgo castellano-leonés son una prueba fehaciente de ello. Fadrique Enríquez supo delegar el almirantazgo en individuos de confianza y aparente capacidad que administraron por representación durante un largo período de tiempo las rentas de la institución con suficiente competencia; ejemplos de ello Luis Ortiz de Gatica, en quién el propio Fadrique delegó la venticuatría de Jerez, donde éste ejercía de lugarteniente de almirantazgo, o Alonso Jofré Tenorio, que ostentó idéntico cargo en la ciudad de Sevilla, o Rodrigo Álvarez de la Becerra.

El almirante no puede competir en influencia con los otros grandes nobles regionales, cuyas redes clientelares y control sobre el terreno eran mucho más amplios que el ostentado por los Enríquez. En la Bahía de Cádiz, pues, se observan más tentativas de recuperar o al menos mantener rentas que un ejercicio real de todos los derechos del almirantazgo, en buena 
medida por la dificultad de ejercer dicha autoridad en un paisaje político tan complicado y polifacético. Paulatinamente, serán los nuevos modelos de gestión instaurados por Isabel y Fernando y reforzados tanto por Carlos V como por Felipe II los que acabarán de finiquitar toda influencia real o teórica del almirantazgo castellano, anulándose muchos de los privilegios de la institución ${ }^{33}$. Por ello, a finales del reinado de Carlos V, y ya a mediados del siglo XVI, la influencia de los almirantes será prácticamente inexistente: los tiempos, simplemente, y como anunciaba siempre cierto cantante, estaban cambiando.

33 J. M. CAlderón OrTega, "El almirantazgo de Castilla: historia de una institución conflictiva", Alcalá de Henares, 2003, 149-150. 


\section{Bibliografía:}

A. M. AnAsagasti VAlDerrama, "Niebla y su tierra en la Baja Edad Media: historia y documentos", Huelva, 2006.

A. COLLANTES DE TERÁN SÁNCHEZ, "Los señoríos andaluces: análisis de su evolución territorial en la Edad Media", Historia, Instituciones, Documentos, 6, 1979, 89-112.

A. Franco SILVA, "Juan Pacheco, privado de Enrique IV de Castilla", Granada, 2012.

A. Franco Silva, "Los Pescadores del Puerto de Santa María y sus problemas a comienzos del siglo XVI", Historia, Instituciones, Documentos, 22, 1995, 191-214.

A. SARriá MuÑoz, I. PÉrez DE COlosía Rodríguez, "Las almadrabas del duque de Medina Sidonia en Tarifa", Baetica. Estudios de Arte, Geografía e Historia, 13, 1991, 241-254.

D. García Hernán, "Los señoríos en la Baja Andalucía en la Edad Moderna”, F. ANDÚJAR CASTILLA, P., DíAZ LÓPEZ, Los señoríos en la Andalucía Moderna. El Marquesado de los Vélez (coords.), Almería, 2007, 77-115.

E. Aznar Vallejo, “Andalucía y el Atlántico Norte a fines de la Edad Media", Historia, Instituciones, Documentos, 30, 2003, pp. 103-120.

E. AZnar VAllejo, "Las rentas del almirantazgo castellano. Entre la ley y la costumbre”, En la España medieval, 37, 2014, pp. 131-163.

E. Cruces Blanco, J. E. López de Coca Castañer, J. M. Ruiz PovedAnO, "Málaga y el Almirantazgo Mayor del Reino de Granada (1510-1538). Revolución y poder”, Málaga, 2017.

E. Martín GutiÉRrez, "El Estrecho de Gibraltar durante el siglo XIV: medio ambiente y redes comerciales en Algeciras", Revista del CEHGR, 30, 2018, pp. 51-69.

E. MARTín GUTIÉRREZ, "Nuevos datos sobre la población y los genoveses en la ciudad de Cádiz: una relectura del padrón de vecinos de 1467”, En la España Medieval, 29, 2006, 187-224.

E. Ruiz PILARES, "El mayorazgo del veinticuatro Pedro Camacho de Villavicencio 'el rico' (1507). El patrimonio del caballero jerezano más acaudalado de su tiempo", En la España Medieval, 35, 2012, 317-347.

E. Ruiz PILARES, "Jerez de la Frontera: el gran centro productor del complejo portuario de Cádiz a finales de la edad media", Estudios sobre patrimonio, cultura y ciencias medievales, 20, 2018, 355-386.

«El Almirantazgo y la bahía de Cádiz en la Baja Edad Media: competitividad...» 
E. Ruiz PILARES, "La sociedad jerezana y su implicación en el comercio atlántico: la producción y el comercio del vino (finales s. XVinicios s. XVI)", J.A. SOlórzano TElecheA, B. ArIZAgA BOLIMBURU, M. BOCHACA (eds.), Las sociedades portuarias de la Europa atlántica en la Edad Media, Logroño, 2016, pp. 337-364.

F. PÉREZ EMBID, "El almirantazgo de Castilla hasta las Capitulaciones de Santa Fe", Madrid, 1944.

I. MONTES Romero-CAMACHO, "Las instituciones de la "saca" en la Sevilla del siglo XV. Aproximación al estudio de la organización institucional del comercio exterior de la corona de Castilla al final de la Edad Media", Historia. Instituciones. Documentos, 31, 2004, 417-436.

J. M. Bello LeÓn, "Los beneficiarios de la Hacienda Real. Privilegios, situados y libranzas en el almojarifazgo mayor de Sevilla a finales del siglo XV. Algunos datos cuantitativos", M. de las M. Borrero Fernández, J. Carrasco Pérez, R. G. Peinado Santaella (coords.) Agentes de los sistemas fiscales en Andalucía y los reinos hispánicos (siglos XIII-XVII), Madrid, 2014, pp. 211-238.

J. M. CAlderón ORTEGA, "El almirantazgo de Castilla: historia de una institución conflictiva", Alcalá de Henares, 2003.

J. M. CALDERÓN ORTEGA, "El almirantazgo de Granada (1512-1538): una historia conflictiva", Revista de Historia Naval, 82, 2003, pp. 7-50.

J. M. GARCíA Avoso, "Poder y conflicto en un señorío atlántico castellano. El pleito del condado de el Puerto de Santa María en los inicios de la Edad Moderna”, Historia, Instituciones, Documentos, 45, 2018. J. M. NAVARro SAINZ. "Aproximación a los gastos señoriales de la casa de los duques de Medina Sidonia a principios del siglo XVI", Huelva en su historia, 3, 1990, pp. 175-194.

M. A. Ladero Quesada, "De Per Afán de Ribera a Catalina de Ribera. Siglo y medio en la historia de un linaje sevillano (1371-1514)", En la España medieval, 4, 1984, 447-498.

M. A. LADERO QUESADA, "Los señores de Andalucía. Investigaciones y señoríos en los siglos XIII a XV”, Cádiz, 1998.

M. GAMBÍN GARCÍA, "Una ayuda inesperada. La decisiva intervención del duque de Medina Sidonia en las conquistas de Tenerife y Melilla (1496-1497)", Revista de Historia Canaria, 196, 2014, pp. 185-2004. M. García Arenal, M. A. DE Bunes, "Los españoles y el Norte de África. Siglos XV-XVIII”, Madrid, 1992. 
P. López Paz, G. Pereira Menaut, "La Tierra y los Hombres: paisaje político, paisaje histórico", Studia Historica: Historia Antigua, 13, 1995, pp. 39-60.

R. SÁNCHEZ SAUS, "Dependencia señorial y desarrollo urbano en la Andalucía atlántica. Cádiz y los Ponce de León en el siglo XV”, Acta histórica et archaelogica mediaevalia, 26, 2005, pp. 903-927.

R. SÁNCHEZ SAUS, "La nobleza andaluza en la Edad Media", Granada, 2005.

R. SÁNCHEZ SAUS, "Las élites políticas bajo los Trastámara: poder y sociedad en la Sevilla del siglo XIV”, Sevilla, 2009.

R. SÁNCHEZ SAUS, "Los Saavedra y la frontera con el reino de Granada en el siglo XV", Estudios sobre Málaga y el Reino de Granada en el $V$ centenario de la Conquista, Granada, 1987, pp. 163-182. 